\title{
TOWARDS SUSTAINABLE PRACTICES IN URBAN DESIGN: THE ROLE OF A SOFTWARE PACKAGE FOR DESIGNING ALTERNATIVE WATER MANAGEMENT METHODS
}

\author{
MARGIER ANTONIN ${ }^{1}$, TRIBOUT SILVERE ${ }^{2}$, BLANPAIN OLIVIER $^{1} \&$ MAJORCZYK VINCENT $^{3}$ \\ ${ }^{1}$ University of Lille, France \\ ${ }^{2}$ University of Grenoble, France \\ ${ }^{3} \mathrm{CDI}$ Technologies, France
}

\begin{abstract}
The emergence of sustainable development has transformed and renewed urban design and architecture principles and practices. Indeed, influenced by sustainable and "green" criteria, planners and designers have included specific issues to their action: low-energy consumption, biodiversity protection, pollution control and water management. Concerning the latter, alternative methods for a sustainable rainwater management have been emerging for the last few decades. In this paper, we present a software we are currently working on for designing alternative water management structures. Issued from a collaborative work between engineers, hydrologists, urban designers and policy makers, this software aims at supporting these stakeholders in dimensioning, volumes calculation, infiltration modeling, etc. It also furnishes a 3D visualisation, thus giving new communication skills. Therefore, this software also acts as a decision support tool concerning alternative methods. Based on semi-structured interviews with urban designers (architects, landscape designers) and engineers, this paper aims at providing an understanding of the role of software on the transition of a socio-technical regime, in this case urban design. More precisely, this paper offers a view on the factors that enable or inhibit the adoption of sustainability-oriented technologies in urban design.
\end{abstract}

Keywords: rainwater management alternative methods, software, sustainable city, urban design, architecture, landscape design.

\section{INTRODUCTION}

Global warming and climate change are one of the most challenging issues of our times. Local actions are needed as well as global solutions for achieving sustainable development. In this way, urban design appears as a means to address environmental issues. Indeed, the city is usually perceived as the most appropriate scale from which innovations and sustainable practices can emerge. Urban planners, architects, engineers have thus a greater and greater role in the transition towards a sustainable development.

Transition studies have shown the importance to understand the socio-technical transitions in a multi-level perspective [1], [2]. In this way, we aim at providing an understanding of the impacts of a niche-innovation - a software for alternative rainwater management - on a sociotechnical regime - urban design. More specifically, this paper offers a view on the factors that enable or inhibit adoption of sustainability-oriented technologies in urban design. In the first section, we describe the socio-technical landscape in which calls for a sustainable transition are significant. In the second section, our methodology and some preliminary results are presented. More precisely, we show how the introduction of software in urban design process questions the practices of the actors involved in transition processes. Finally, in conclusion, we present general reflections about those transformations. 


\section{URBAN DESIGN: A SOCIO-TECHNICAL REGIME IN TRANSITION}

\subsection{Urban design challenged by sustainable development and internationalization}

Over the last decades, the growing and uncontrolled urbanization as well as global warming effects have led to major transformations in urban design. The rise of the "antrohopocene" in scientific and media discourses indicates the growing awareness of the impacts of human activity on planet earth. As Latour [3] says, it underlines "the urgency of the preparations" to maintain a sustainable ecosystem. These preparations appear in all areas of social life, at every scale, and are expressed through different regulations which aim at modulating our way of life to encourage the sustainability of our planet. The global inducement to sustainable practices is particularly significant in urban design. There are nowadays emerging policies and institutional regulations that modify practices and that tend to transform the making of the city into a sustainable one. Whether it be about energy performances of buildings, rainwater management, independence from non-renewable energy sources, making the city requires new technical skills and new forms of cooperation. In this way, we are currently witnessing an ongoing diversification of the actors involved in the making of the city as well as their fields of expertise.

The environmental imperative is associated with the emergence of competitive logics in the making of the city. In fact, new urban projects are usually used as a means to valorize and insert a city in the network of global cities. Economic forces have then been incorporated into the urban project. As a result, policy makers often call on famous architects and designers over the world for branding the city. This internationalization of urban design also creates competition between urban design actors. If they want to survive, they have to reduce their effective costs and the amount of time dedicated to activities that are non-profitable in the short term.

That constraining context is one of the reason explaining the rise of software and computer based tools in urban design practices. Most of these tools aim at gaining time and at giving new competencies. For example, about sustainable design, there are many software dedicated to rainwater management or renewable energy issues, allowing non-experts to gain knowledge and practical skills about those issues which are usually associated with engineering. We assume in this paper that software are not neutral and that they impact the practices of design, cooperation and communication.

\subsection{Software in urban design}

Some authors have already focused on the use of software and computer-based tools in architecture and urban design. Sennett [4] has critically described the transformation of the thought process that usually emerges from hand drawing. According to him, the time dedicated to drawing permitted to become aware of the specificities of the fieldwork. By accelerating the creative gesture, computer based tools would reduce the quality of reflections issued from hand drawing. Another criticism is related to the standardization of the design practices. The banalization of the use of these tools from the beginning of the project would induce designers to follow the templates provided by the software. By encouraging a "rationalization of the thought" [5], that way of designing abolishes the "vague and the indefinite" [6] which stimulates the creative process and might open on new ideas. Another concern is about the growing importance of the visual communication in the practice of the project. 
Because of the primacy of the image in architectural and design competitions, designers nowadays must be able to produce high quality $3 \mathrm{D}$ visuals. But the $3 \mathrm{D}$ and aesthetic rendering of a project only represents a small part of its reality. Without raising the point that all architectural thoughts are not reducible to a graphic representation.

But, there is another transformation that has less been dealt with: the role of software on the sustainability transition of urban design. Indeed, software often give new skills and opportunities for a sustainable making of the city. Henceforth, we would like to raise some questions: how do the actors involved in urban design mobilize software in the realization of sustainability transition? Are these tools perceived as a standardization process of their work or, on the contrary, as a promise of new creative opportunities? How do they impact the working relations between the different actors involved in urban design?

\subsection{A niche-innovation: a software for sustainable rainwater management}

Regarding rainwater management, urban designers must respect a plethora of regulations which make urban sustainable design a complex process. Besides, urban designers often lack a sufficient ecological knowledge about hydrologic issues to integrate as effectively as possible alternatives methods for rainwater management within their projects. Hence, in that complexification of the making of the city, they make use of engineers' services or they try to acquire the required skills as an internal expertise (to be able to integrate sustainable criteria into their practice). In that way, we created a software which aims at creating a collaborative platform on which could work architects as well as landscape designers or engineers (at different levels of uses according to each stakeholder's competencies). The idea is to make people able to deal with sustainable techniques for rainwater management even if they do not possess the required scientific and hydrologic skills. In this way, the sustainable issues might be grasped by all the actors and introduced in the first steps of the project.

Our research is directly issued from the elaboration of this software. This project was initially development-oriented, the main goal was the creation of a software dedicated to the professionals of urban design. Most of the participants were engineers, hydrologists, policy makers and urban designers. However, the presence of a social science researcher in the project provided another view on what was at play in this process. Indeed, different facts occurring during the process attracted his attention. For example, the comments of each partner during the meetings varied greatly according to their own expertise and their role in urban design. These comments ranged from suspicion to euphoria, which was interesting for a social science researcher. That new gaze on what "does" this software on labor practices invited the team to develop a research dedicated to the influence of software on urban design.
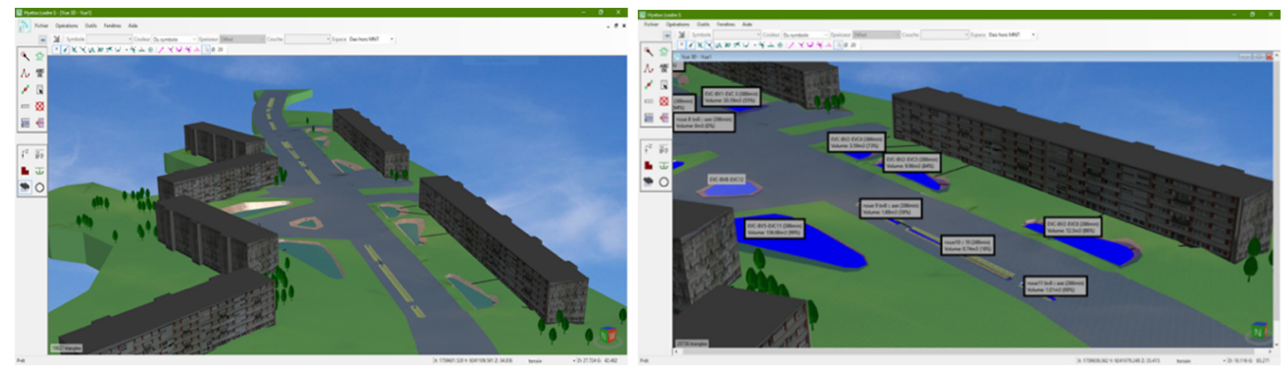

Figure 1: 3D visuals issued from the software Hyetos. 
To this end, another social researcher has then been included in the project and we decided to interview urban designers. The main goal was to understand the role of software on the sustainability transition in urban design practices as well as the pathways to this transition.

In this way, this research is inspired by the transition studies and the multi-level perspective which is a fruitful framework for analyzing the socio-technical innovations. In this perspective, transition is considered as changes from one sociotechnical regime to another, and it would result from the interactions between 3 levels: niche-innovations, sociotechnical regimes and sociotechnical landscape [1]. To understand the factors which enable or inhibit the adoption of a sustainability-oriented software, we focus on urban design as a socio-technical regime. The latter is defined as: "the rule-set or grammar embedded in a complex of engineering practices, production process technologies, product characteristics, skills and procedures, ways of handling relevant artifacts and persons, ways of defining problems - all of them embedded in institutions and infrastructures" (Rip and Kemp cited in [2]).

However, despite its interest for analyzing transition, this theoretical approach has often been criticized for not paying enough attention to agents [7]. Then, we aim, in this research, to emphasize on the micro level of transition for a better understanding of the impacts of a niche innovation on a sociotechnical regime.

\section{RESULTS}

\subsection{Influences on the socio-technical regime}

In this way, we present below some preliminary lines of thought issued from the first interviews. At that moment, this research is only based on 6 semi-structured interviews we realized with architects, urban designers and engineers. Their own experience of alternative

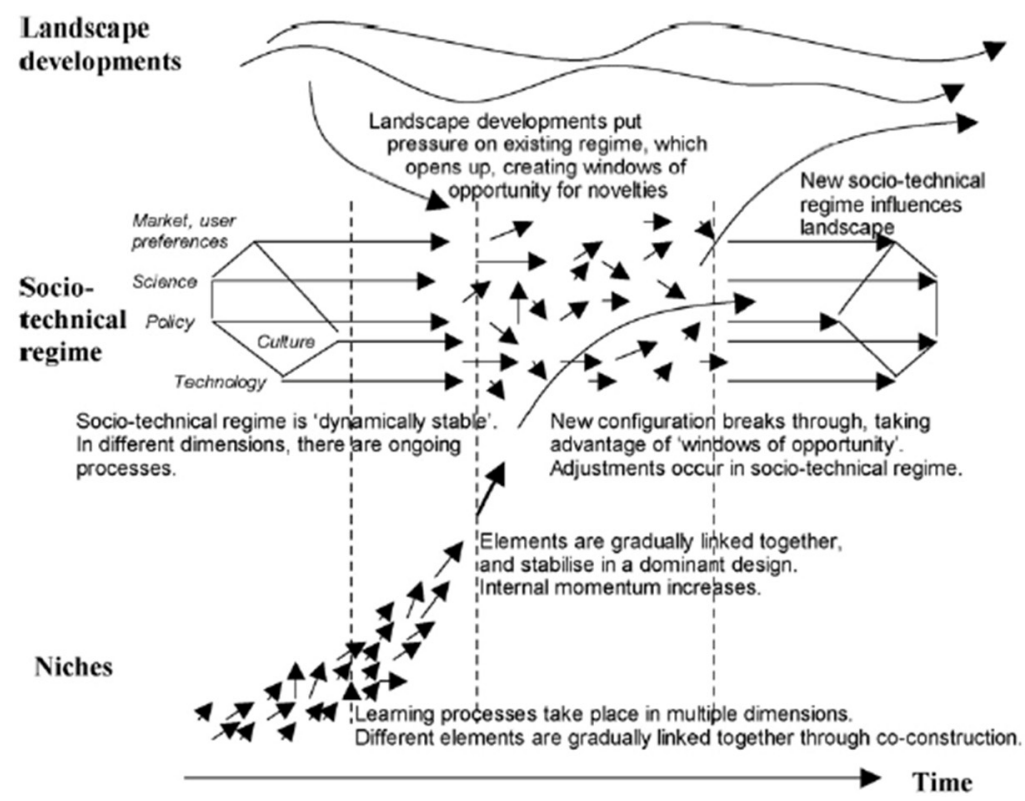

Figure 2: A multi-level perspective on system innovations [2]. 
methods for rainwater management are different but they all must deal with a growing demand for sustainable practices. The software we created was presented during interviews in order to generate reactions and to bring out some representations.

\subsubsection{Competencies}

Most of the architects and urban designers admit they do not have a sufficient knowledge to successfully design alternative methods for rainwater management. However, as it is nowadays often asked by the masters of works, they are interested in these methods and they usually have to make use of engineers' services for designing those techniques. But that collaboration with an external service provider has a significant cost. Then, if the presented software is perceived as too technical by architects and urban designers, they found it interesting for a greater independence. They do not want to dispense with engineers but they want to be able to start as soon as possible their reflections and to get a first insight about the quality of their rainwater management project before calling on engineers.

Concerning engineers with an expertise in urban hydrology and alternative methods, the point of view is quite different. According to them, a software cannot replace the skills required to design efficiently alternative methods. As one of them told us: "There are professions, it's not an accident that there are professions [...] It's like landscape design, landscape design is a real profession. Then urban hydrology is also a real profession!". This quote reflects the idea that such a software cannot be efficiently used without experts, whatever the quality of the software is. For engineers, this software is going to be used by architects and landscape designers without a real expert view on their results. There are worried that the use of this kind of software finally reduces the sustainable qualities of the projects more than it gives new skills. These comments finally reflect the worries to be dispossessed of their own skills and to lose their dominant position as expert in the design of alternative methods.

\subsubsection{Cooperation and competition}

The software is perceived both by architects and engineers as "an interactive interface between architects, landscape designers and engineering offices", which could facilitate the discussion between actors. For architects, it appears as much more intuitive than calculation tables and the collaboration with engineers could be easier. Engineers also agree that their technical expertise is complex to explain to their partners and that this simplification of the results would be welcome. The software then could be used as a "medium for discussion". Another point mentioned by architects is that it is important to be competent on the tasks they outsource to engineers if they want to be in position to negotiate the costs. If they have knowledges about alternative methods and if they manage to get a first insight of the results, they can be confident about their project and they only need to request a control of the project instead of the whole study for the project. In this way, the software is perceived as a means to save money.

\subsubsection{Communication}

A concern which is shared by all the interviewees is the usefulness of the visual representation for communication. They all expressed their difficulties to convince policy makers and masters of work about the efficiency of alternative methods for rainwater management. In this perspective, the graphic representation of the results, the visual representation of the integration of alternative methods in the landscape, the $3 \mathrm{D}$ visualization of the hydraulic simulation, are positively perceived. The results could be used as a proof of the importance of alternative methods for rainwater management but also as the confirmation 
of their own expertise. Moreover, both architects and engineers see the opportunity for sensitizing citizens to sustainable issues. And for architects, it is also a means to remove potential concerns about the visibility of alternative methods in the landscape.

\subsubsection{Standardization}

Regarding the announced standardization of urban design through software, the interviewees are sceptical. If users accept the results as the only solution, there is clearly a risk of standardization of rainwater management practices. But, as urban designers, most of them estimate that they use this kind of software with a distance, as a way to question their project and not as a way to design automatically projects in place of designers and engineers.

\section{CONCLUSION}

This micro-level approach reveals some concerns about sustainability-oriented software. In a paradoxical way, the presented software appears, on one hand, as a resource, giving new skills and new opportunities, and on the other hand, as a constraint for different reasons. Regarding positive points, the software appears as an opportunity to enhance their own competencies in a hyper-specialized and tight market, to gain independence, and by the way, to save money. Through the example of the comments by professionals on a software for sustainable design, we realized that the pathway to sociotechnical transition is mainly dependent of the possibilities to address economic challenges. It's too early to draw significant conclusions, but we must admit that environmental concerns are almost absent from the discourses. It seems that sustainability-oriented software are mainly evaluated according to their economic promises more than to their ecological efficiency. The software is also perceived as a constraint, because it needs time and many adjustments to efficiently use a new software in a design agency but also because some of the actors do not want to be overworked with tasks they don't have initially to do. But even if we notice some inhibitions in the diffusion of this type of software for a sustainable design, there are transformations of the practices. As Genus and Coles [2] say, "the diffusion pattern [of novel technology] produces a new set of socio-technical relations" (p. 1438). In that case, the diffusion of a sustainability-oriented software transforms the ways actors interact and work. Indeed, by making easier and accessible the design of alternative water management methods, the software gives the opportunity to non-specialized actors to grasp of this sustainable issue and to be less dependent on engineers and hydrology experts. By revealing the differences in the way the actors perceive the software, the interviews also point out some fears about the recomposition of the field of urban design which is at play in the sustainability transition. That especially points out the uncertainty of professional identities in this context and the relations of power that also drive the sociotechnical transition. This paper finally claims for a better understanding of the interactions between the different actors involved in sustainable innovations in urban design. That is a way to clarify the complexities of transitions which are unfolding at the macro level.

\section{REFERENCES}

[1] Geels, F.W \& Schot, J.W., Typology of sociotechnical transition pathways. Research Policy, 36(3), pp. 399-417, 2007.

[2] Genus, A \& Coles A.M., Rethinking the multilevel-perspective of technological transitions. Research Policy, 37 (9), pp. 1436-1445, 2008.

[3] Latour, B., The Anthropocene and the Destruction of the Image of the Globe, Gifford Lecture, University of Edinburg, 2013.

[4] Sennett, R., The craftsman, Penguin, 2009. 
[5] Leglise, M., Informatique et architecture : la grande illusion, Conference Scan 16, 2016.

[6] Amphoux, P., Ambiance et conception: de l'analyse des ambiances à la conception architecturale et urbaine, Actes de la conférence internationale Herbert Simon, pp. 19-32, 2002.

[7] Farla, J., Markard, J., Raven, R \& Coenen, L., Sustainability transitions in the making: A closer look at actors, strategies and ressources, Technical Forecasting and Social Change, 79 (6), pp. 991-998, 2012. 